\title{
varia
}

\section{"Ferdinandus Ortiz faciebat..." A propósito de la imagen de Santa Teresa para los Carmelitas de Alcaudete (Jaén)}

\author{
Francisco Rojas Serrano \\ Investigador vinculado a la Universidad de Jaén
}

Málaga, 1760. En este año, el escultor Fernando Ortiz realiza una obra representando a Santa Teresa [1] por encargo del Convento de la Encarnación, vulgo del Carmen, de Padres Carmelitas Descalzos de la villa de Alcaudete (Jaén).

Lejos de constituirse como un amplio estudio sino más bien como unas notas referentes a la obra en cuestión, la intención del presente trabajo se orienta a destacar la figura de un escultor un tanto olvidado como es Fernando Ortiz, algo que no obstante está cambiando en los últimos años con la publicación de distintos estudios sobre su obra. En este sentido debemos apuntar que no nos encontramos frente a un escultor de segunda fila, sino ante toda una sobresaliente figura del quehacer artístico español del Siglo de la llustración ${ }^{1}$. Fernando Ortiz nace hacia 1717 en Málaga, desconociéndose por el momento los datos referentes a su formación como escultor. Romero Torres señalaba en $1981^{2}$ el posible aprendizaje en el taller de Miguel Félix de Zayas, escultor este último formado a la sombra de Mena. No obstante, deja abierta la posibilidad de que fuese José de Medina (escultor malagueño activo en Jaén en el siglo XVIII) el verdadero encargado de formar a Ortiz en el difícil mundo de la escultura. Ambas teorías aparecen respaldadas, años más tarde, por Sánchez López que apunta a la posibilidad de que existieran contactos simultáneos entre un taller y otro ${ }^{3}$. Sea como fuere, la formación de Fernando Ortiz da paso al periodo que, sin duda, marcará su producción escultórica de ahí en adelante. Nos estamos refiriendo a su paso por la Corte en 1756 en donde se le nombra Perito de las canteras andaluzas, con la difícil a la par que notoria misión de seleccionar los materiales que iban destinados a la construcción del nuevo Palacio Real ${ }^{4}$. Su puesto al servicio del rey se verá compaginado con encargos desde otros lugares de la

* ROJAS SERRANO, Francisco: “Ferdinandus Ortiz faciebat...'A propósito de la imagen de Santa Teresa para los Carmelitas de Alcaudete (Jaén)", en Boletín de Arte, $\mathrm{n}^{\circ} 29$, Departamento de Historia del Arte, Universidad de Málaga, 2008, págs. 539-547.

1 SÁNCHEZ LÓPEZ, Juan Antonio y LÓPEZ-GUADALUPE MUÑOZ, Juan Jesús: "Renovarse o morir. Panorámica de la escultura andaluza y mediterránea en tiempos de José Luján Pérez (1756-1815)", en VV.AA.: Luján Pérez y su tiempo, Gobierno de Canarias, Las Palmas de Gran Canaria, 2007, págs. 81-97.

2 ROMERO TORRES, José Luis: "Fernando Ortiz: aproximación a su problemática estilística", Boletín del Museo Diocesano de Arte Sacro n 1-2, Servicio de Publicaciones Málaga, 1981, págs. 148-149.

3 SÁNCHEZ LÓPEZ, Juan Antonio: "Fernando Ortiz: aires italianos para la escultura del siglo XVIII en Málaga", Actas del XI Congreso Nacional de Historia del Arte, CEHA, Valencia, 1996, pág. 168.

4 ROMERO TORRES, José Luis: "Los escultores andaluces y el sueño de la Corte", en Actas del III Congreso de Historia de Andalucía: Historia Moderna, Cajasur, Córdoba, 2002, págs. 282-300 [vol.3]. 


Q: varia $\quad$ Francisco Rojas Serrano

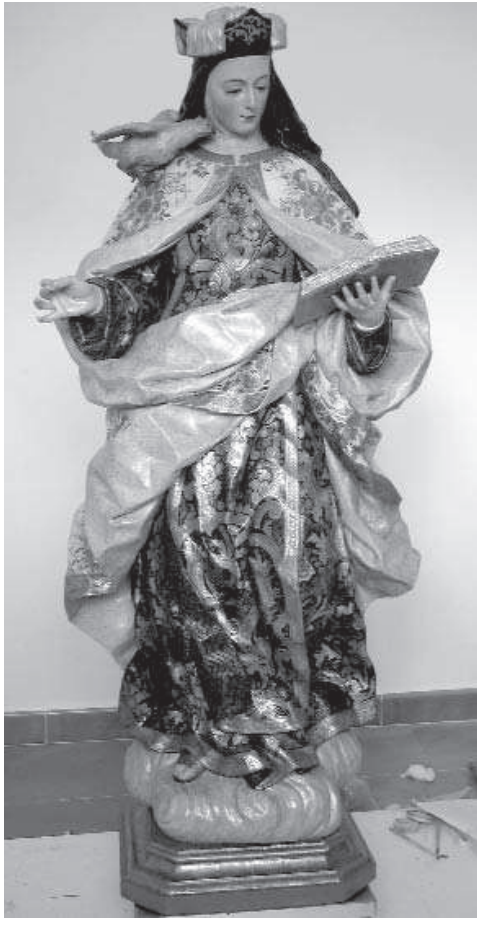

1. Fernando Ortiz. Santa Teresa (1760).Visión frontal. geografía española, como es el caso de la imagen que nos ocupa. Su cargo y sus relaciones con la Corte se mantienen al menos hasta 1763 , siendo ya una constante de su obra el tratamiento "marmóreo" impreso a sus esculturas en madera.

En relación con lo señalado en los párrafos anteriores, sirvan, por tanto, estas líneas para dar a conocer una obra inédita hasta ahora, así como para la reivindicación de su producción artística y del alcance de su figura que lo hacen merecedor como hemos dicho- de un puesto destacado dentro del panorama escultórico del Barroco en España.

\section{CONTEXTO HISTÓRICO DE LA OBRA.}

Con anterioridad al estudio propiamente dicho de la pieza, debemos plantear unas consideraciones que nos ayuden a comprender el contexto histórico en el que se enmarcan la obra y su autor. De esta manera, y remitiéndonos al ámbito específico del encargo y sus circunstancias, el Convento de la Encarnación de Alcaudete se funda por escritura dada el 10 de octubre de 1590 a D. Francisco de Córdova y

Velasco, IV Conde de Alcaudete, y a su esposa $D^{a}$ Ana Pimentel ${ }^{5}$, pasando en sus primeros años por una fase de crecimiento que lo llevaron a ocupar una primitiva morada provisional en unas casas cercanas a la Plaza del pueblo, cedidas al efecto por su benefactor. Con el tiempo se levantó el nuevo edificio, fechable en el siglo XVII y estudiado por Galera Andreu6. El autor apunta el estrecho seguimiento en este inmueble de los prototipos ya establecidos por los Carmelitas en otros de sus templos; a saber, iglesias de una sola nave, corto crucero, cúpula encamonada sobre pechinas, capillas laterales, fachada con frontón triangular rematando el conjunto, etc. Dicho en otras palabras, nos encontramos ante un templo netamente sintonizado con los presupuestos de la Reforma Católica, al servicio pleno de la comunidad destinada a habitarlo. Es entonces cuando debemos suponer que se produjo el

5 RIVAS MORALES, Antonio: Guía Artística de Alcaudete. Arte y Religión, Editorial Benamazor, Granada, 2000, pág. 94 . 
mayor auge vivido por la comunidad, sobre todo a partir de los hechos milagrosos atribuidos a la imagen de Jesús Nazareno que se veneraba en dicho templo ${ }^{7}$. Fruto de la eclosión devocional generada por esta escultura es lógico pensar que las arcas conventuales no hicieran sino aumentar considerablemente a lo largo de los siglos XVII y XVIII, con la consiguiente profusión de encargos a remunerados artistas.

Es evidente que el exagerado "consumismo" de arte sacro (bien en forma de pinturas o esculturas) de esta época tendrá su justificación plena en un acontecimiento de gran calado en el campo del arte como es el Concilio de Trento (15451563), impulsor a posteriori de los postulados y recomendaciones a seguir en materia de representaciones de santos y de escenas religiosas. A propósito de lo dicho, conviene señalar la respuesta de la Iglesia Romana al avance del Protestantismo, impulsando, de puertas hacia adentro, la llamada Reforma Católica, con el objeto de vencer la partida en terreno propio y plantar cara al nuevo movimiento religioso mediante la autoafirmación en las propias tesis. En esta difícil tarea, el Catolicismo tendrá la ventaja de contar entre sus filas con dos españoles que serán claves para entender el cambio: Juan de Yepes Álvarez y Teresa de Cepeda y Ahumada, o lo que es lo mismo, San Juan de la Cruz y Santa Teresa de Jesús.

Quedamos por tanto ubicados en plenos años del Barroco, ante un convento carmelita de abundantes recursos fruto del culto al Nazareno que los frailes tanto promueven desde la propia Orden. Si bien, la destrucción y extravío de toda documentación acerca del establecimiento durante las desamortizaciones del XIX y la Guerra Civil condiciona, y mucho, la labor investigadora sobre los bienes muebles que en él se custodiaban y que, en parte, va a verse fundamentada en hipótesis, conjeturas o suposiciones.

Como era de esperar, y debido a los principios de la orden promotora, el culto hacia los santos carmelitas no tardó mucho en afianzarse, sirviendo como ejemplo la imponente talla del profeta Elías, obra del siglo XVII atribuida a Pedro de Mena. Es de suponer que San Juan de la Cruz gozase así mismo de veneración constante en la iglesia al margen de la representación pictórica existente en uno de los lunetos del crucero. Sin embargo, la referida pérdida de toda documentación y de la práctica totalidad de los bienes muebles sumerge en la sombra lo que vendría a ser casi una certeza. En este contexto debemos situar el encargo a Fernando Ortiz de la escultura estudiada. No obstante, y con antelación a estos años, ya existía en el templo una representación pictórica de la santa (compañera a la de San Juan de la Cruz) con un carácter más decorativo, que afortunadamente se ha conservado hasta nuestros días. El motivo fundamental del encargo de la nueva talla podemos encontrarlo en el nombramiento de Santa Teresa como patrona de la Villa. Desconocemos la

6 GALERA ANDREU, Pedro Antonio: Arquitectura de los siglos XVII y XVIII en Jaén, Caja de Ahorros y Monte de Piedad, Granada, 1979, pág. 60.

7 Para más información sobre la devoción y culto al Nazareno véase REYES, Fray Jerónimo de los: Tratado de la prodigiosa imagen de Jesús Nazareno de Alcaudete (Granada, Imprenta de los Reyes, 1661), Ed. Facsímil de RIVAS MORALES, Antonio, Granada, 1991. 


Q: varia $\quad$ Francisco Rojas Serrano

fecha en la que pudo darse la proclamación aunque sería posible que hubiese venido de la mano de la beatificación (1614) o bien de la canonización (1622), siendo esta última opción más probable. Lo que es irrefutable es que en 1752 el patronazgo estaba solidamente definido. Así se desprende del Catastro del Marqués de la Ensenada ${ }^{8}$, por cuanto en esas fechas se afirmaba que Santa Teresa era patrona por parte de los propios vecinos. No es de extrañar, pues, que ocho años más tarde se encargase la hechura de una nueva talla a Fernando Ortiz.

Como explicación al hecho de que Santa Teresa llegase a alcanzar el patronazgo de una villa con la que aparentemente no guardaba relación especial alguna, debemos sopesar la posibilidad real de que la santa de Ávila pernoctase una noche en el convento de Franciscanas de Santa Clara en marzo de 1575, según reza una inscripción en el interior del citado cenobio 9 . La destrucción casi total del recinto conventual nos impide conocer, a ciencia cierta, si en realidad se produjo esa visita a Alcaudete o si es producto de leyendas y creencias populares; pero en cualquier caso, el peso de los Carmelitas del Convento de la Encarnación podría haber sido suficiente para la proclamación de Santa Teresa como patrona de la ciudad hasta su desplazamiento en pro de la imagen de Nuestra Señora de la Fuensanta ya en el siglo XIX.

Si para 1752 la Santa de Ávila ostentaba el referido patronato, es obvio pensar que ya existía una escultura de la misma, si bien, debió cambiarse por no ser del gusto del pueblo a la par que para acomodarse a los gustos barrocos imperantes del momento. En consecuencia, en 1760 se le encarga al célebre escultor malagueño Fernando Ortiz (que para entonces ya había regresado de la Corte) la hechura de una imagen de Santa Teresa [2] estéticamente renovada y conforme a las tendencias del momento.

Desconocemos las cláusulas que pudieran contemplarse en el contrato firmado entre los frailes y el escultor, pero debido a las reducidas dimensiones de la talla (apenas $124 \mathrm{cms}$.) suponemos que pudo ir acompañada de un retablo en el que se le rindiese culto, por cuanto una refundadora de la Orden e intercesora tutelar del pueblo, no podía contentarse con ser personaje secundario de otro programa iconográfico. A partir de entonces, la santa de Ávila será venerada dignamente en el convento de los Carmelitas Descalzos de manera ininterrumpida hasta el año 1936, cuando el capellán de la iglesia la retira del culto por miedo a su posible destrucción en una guerra que no había hecho nada más que comenzar ${ }^{10}$. Al término de la contienda, carente de altar y de retablo la imagen quedó almacenada en la sacristía del templo a la espera de ser repuesta al público. Sin embargo, han tenido que pasar casi ocho décadas para que la escultura haya recuperado el sitio que se merece junto al presbiterio, gozando por otra

\footnotetext{
8 RIVAS MORALES, Antonio: op. cit., pág. 110.

9 La inscripción reza asi: "En el 1575 en el mes de marzo pernoctó en este convento y en esta habitaciónenfermería la mística doctora Santa Teresa de Jesús. El descanso de su jornada fue consagrar las horas que debía al reposo a cuidar a las religiosas enfermas. Dioles la dulce medicina de su espíritu, consolándolas y fortaleciéndolas."
}

10 RIVAS MORALES, Antonio: op. cit., pág. 113. 


Q: varia "Ferdinandus Ortizfaciebat..."

\footnotetext{
2. Santa Teresa. Pormenor del busto y rostro.
}

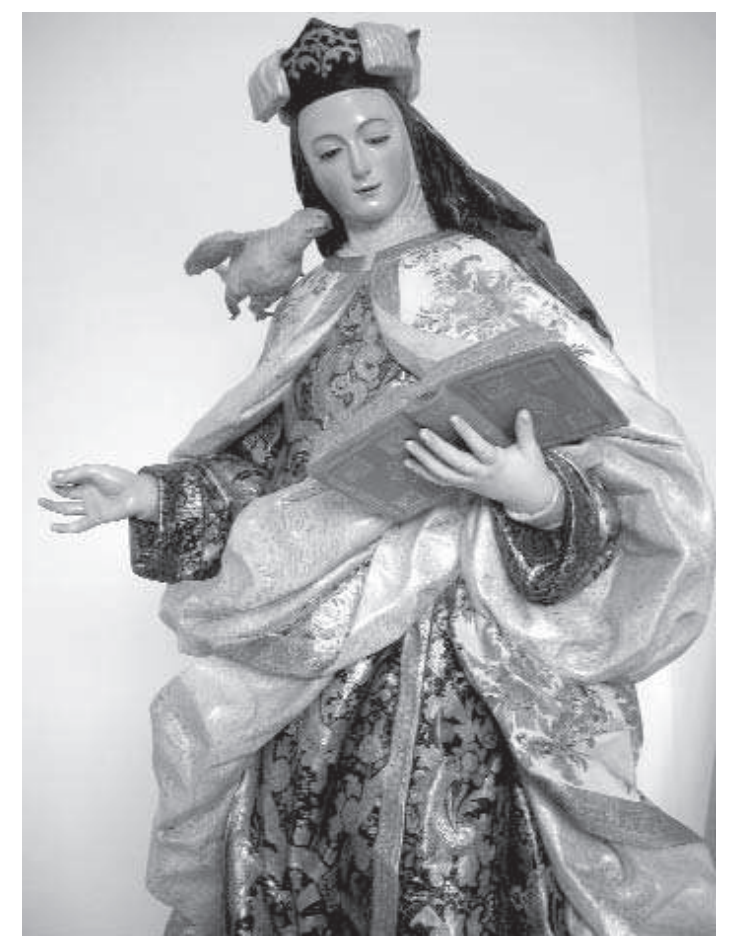

parte de un remozado estado de conservación tras la restauración a la que fue sometida, en julio de 2007, por parte de Sara Gómez Cantero ${ }^{11}$.

\section{ANÁLISIS DE LA OBRA.}

Centrándonos ya en los aspectos iconográficos y formales de la imagen debemos ponerla en todo momento en relación con la producción escultórica de su autor. La paternidad segura de Ortiz sobre la obra nos permite establecer una serie de paralelismos entre esta pieza de Alcaudete y otras esculturas atribuidas hasta ahora, cuya adscripción al catálogo de Fernando Ortiz puede salir reforzada después del estudio de esta Santa Teresa.

Por el reducido tamaño de la imagen, a la par que por su importancia, señalábamos anteriormente su posible ubicación en un retablo de una de las capillas laterales o del crucero. La destrucción de los bienes muebles del convento en 1936, de

\footnotetext{
11 Desde aquí mi gratitud a Sara Gómez Cantero, dado que las ilustraciones que acompañan a este texto son obra suya y están tomadas de los informes de restauración que se encuentran en el Archivo Parroquial de Santa María de Alcaudete.
} 


Q: varia $\quad$ Francisco Rojas Serrano

una forma brutal como aparece relatado parcialmente en la obra del investigador local Telesforo Ulierte ${ }^{12}$, nos priva de conocer sus programas iconográficos así como sus estructuras. A ello debemos añadir la inexistencia hasta ahora de documentos gráficos, al contrario que ocurre con el vecino Convento de Santa Clara o con la Parroquia de Santa María, que desvelaban cómo era exactamente el interior de la iglesia con el objeto de poder recrear la organización de altares y la ubicación exacta de la escultura que estamos tratando.

Nos encontramos ante una de las obras más logradas del genio malagueño. Dentro de la producción de Ortiz lo que más abundan son las imágenes procesionales de santos y representaciones pasionistas además de numerosas Dolorosas, siendo precisamente éstas las más propensas a sufrir desafortunadas restauraciones según varíen los gustos del momento. En el caso de la imagen de Santa Teresa no podemos afirmar si en su día procesionó por las calles de Alcaudete o no, pero es posible que así fuera debido al referido patronato, además de darse el hecho de estar finamente trabajada en su totalidad, atendiendo al mismo gusto por el detallismo preciosista, sin limitaciones en ninguna zona. No obstante, la ausencia de documentación que pruebe nuestras hipótesis hace imposible saber si la imagen pudo haber sido objeto de algún culto externo o quedó relegada al ámbito de la iglesia del convento.

Pasando al análisis de la obra en sí, es obligado señalar las excepcionales calidades del acabado de la pieza. Toda ella es un puro juego barroco que utiliza como instrumentos teatrales el vuelo de los pliegues de las vestimentas, a los que debemos unir unos magníficos estofados en el hábito de la Doctora de la Iglesia. Ya apuntaba Juan Antonio Sánchez López la capacidad de Ortiz para transmitir a sus obras el carácter marmóreo de la escultura que tanto había admirado e incluso cultivado en su periodo en la Corte e inmediato al mismo ${ }^{13}$, y en este caso se cumple por completo tal precisión. Los voladizos pliegues se recortan y doblan entre sí con la misma capacidad con la que se trabajaba el mármol para esculturas monumentales. Muestra de esta característica de Fernando Ortiz la podemos ver en la Inmaculada que hiciese para el Triunfo del antiguo Convento de San Pedro de Alcántara de su ciudad natal 14 o en el grupo de los Filósofos encargado a Ortiz para una de las cuatro galerías principales del Palacio Real de Madrid ${ }^{15}$ concluido por estas fechas, ambas obras realizadas en mármol. En este sentido debemos apuntar al nombramiento y encumbramiento de Fernando Ortiz; recordemos que era Académico de Bellas Artes de San Fernando desde 1756 como encargado de supervisar los mármoles cuyo fin era la construcción y decoración del nuevo Palacio Real que iba a sustituir al antiguo

\footnotetext{
12 Véase ULIERTE RUIZ, Telesforo: Orígenes de la Cofradía de Nuestro Padre Jesús Nazareno, Granada, 1985.

13 SÁNCHEZ LÓPEZ, Juan Antonio: "Fernando Ortiz", pág. 173.

14 SÁNCHEZ LÓPEZ, Juan Antonio: "Inmaculada Concepción”, en VV. AA.: Patrimonio Cultural de Málaga y su provincia. Málaga, Diputación de Málaga, 2001, págs. 190-193.

15 ROMERO TORRES, José Luis: “Fernando Ortiz: aproximación a su problemática estilística”, págs. 151-152.
} 
Alcázar de los Austrias, incendiado en la Nochebuena de 1734. Este contacto directo con materiales de primera calidad se unió al conocimiento que Ortiz tenía de las esculturas marmóreas realizadas en la Italia del Barroco, más concretamente los excelentes trabajos llevados a cabo por la vertiente más clasicista encabezada por Alessandro Algardi, en contraposición al dinamismo de Gian Lorenzo Bernini. Así las cosas, en la biografía del artista malagueño es clave el trato con los escultores italianos que acudieron a la Corte llamados por la Corona para concluir el Palacio Real y con los que Ortiz mantuvo relación personal y profesional durante sus años en Madrid ${ }^{16}$.

Así pues, la obra que mostramos presenta toda una serie de características que la entroncan de manera directa con la producción anterior de Fernando Ortiz. La composición es puro capricho y movimiento que contrastan con el rostro tendente al clasicismo, sereno y pausado de la Santa, que aparece redactando una de sus obras. Por un momento parece que el misticismo impregnado a sus obras emerge del libro para contagiar a Santa Teresa que, pacientemente, sigue lo dictado por la paloma que apenas si se posa sobre su hombro. La representación del rostro de la Santa presenta unas carnaciones casi marfileñas y suaves que otorgan mayor delicadeza a la pieza, tan sólo salpicadas con dos de los tres pintorescos lunares que recoge su confesor Francisco de Ribera en la descripción que realiza de Teresa ${ }^{17}$ y que sutilmente introduce Ortiz en esta talla, sin privarla en ningún momento de la gracia y belleza del rostro. Es precisamente en la configuración de este último donde puede apreciarse ciertas similitudes formales con la imagen de San Miguel Arcángel que se conserva en el Museo de Arte Sacro de la Abadía Cisterciense de Málaga ${ }^{18}$, obra que por otro lado está atribuida al círculo de Ortiz y que creemos pudo salir de manos directas del maestro debido a las estrechas semejanzas con esta escultura alcaudetense. En ambas obras las carnaciones son de tonalidades claras, otorgando mayor delicadeza si cabe a la pieza además de presentar semejantes estofados; Santa Teresa en la capa y San Miguel en el faldellín.

Con respecto a las vestiduras, la Santa aparece tocada con el hábito carmelita, eso sí, exuberantemente decorado a base de finísimos estofados. La túnica presenta decoración de flores, rocallas y demás elementos vegetales sobre un fondo salpicado en toda su superficie con elementos esgrafiados y picados en horizontal que provocan que los tonos dorados y negros se fundan para dar una imagen lustrosa a la pieza. La capa, unida a la altura del cuello, es de color blanco y en ella podemos ver una sucesión de ramilletes florales que conjugan el estofado con detalles pictóricos a base

\footnotetext{
16 TÁRRAGA BALDÓ, Ma L. Giovanni Domenico Olivieri y el Taller de Escultura del Palacio Real, 3 vols., Patrimonio Nacional-CSIC-Instituto Italiano de Cultura, Madrid, 1992, pág. 71 (vol.2).

17 Véase la obra: RIBERA, Francisco de: Vida de la madre Teresa de Jesús. Edibesa, 2004. El autor describe el rostro y sus lunares tal que así: "En la cara tenía tres lunares pequeños al lado izquierdo, que le daban mucha gracia, uno más abajo de la mitad de la nariz, otro entre la nariz y la boca, y el tercero debajo de la boca".

18 SÁNCHEZ LOPEZ, Juan Antonio: "Abadía Cisterciense de Santa Ana. Museo de Arte Sacro". Málaga, Ayuntamiento, 1997, págs. 9-10.
} 


Q: varia $\quad$ Francisco Rejas Serrano

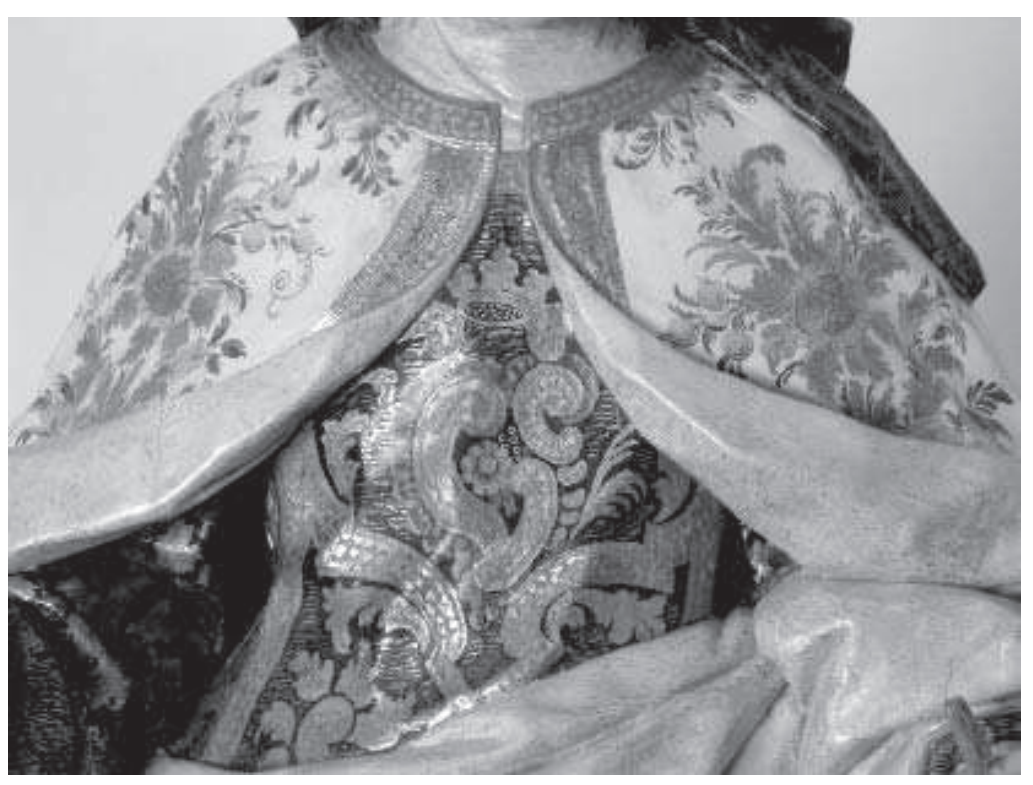

3. Pormenor de los estofados del hábito.

de una llamativa policromía [3]. Tanto la túnica como la capa destacan por aparecer bordeadas con una cenefa dorada de exquisito gusto y cuidado en su elaboración que ponen de manifiesto el afán preciosista de Ortiz en el acabado de sus obras.

Para representar su categoría como escritora mística aparece la Santa tocada con un birrete. Dado que, como aludíamos líneas más arriba, aparece en pleno ejercicio de la escritura de alguno de sus conmovedores poemas, mientras usa una estilizada pluma que se dispone a aplicar sobre el libro que porta en su mano izquierda. Si los poemas de Santa Teresa son reveladores desde el punto de vista espiritual, el libro que sostiene la imagen que nos ocupa lo es desde el punto de vista histórico artístico, ya que en él aparece la firma autógrafa de Fernando Ortiz acompañada de datos de enorme interés. El texto completo es el siguiente: "Ferdinandus Ortiz faciebat Malaçe Anno Domini MDCCLX. Academicus Regis in Matritensi". Nos encontramos por tanto ante la evidencia clara y firme de la autoría de Fernando Ortiz mediante su propia firma, algo ya repetido en otras obras del autor como el San Juan

\footnotetext{
19 PATRÓN SANDOVAL, J.A. y ESPINOSA DE LOS MONTEROS SÁNCHEZ, Francisc: "Notas sobre la producción del escultor malagueño Fernando Ortiz para Tarifa (Cádiz)", en Boletín de Arte, $\mathrm{n}^{\circ}$ 26-27, Universidad de Málaga, 2005-2006, págs. 806-810.
} 
1. varia "Ferdinandus Ortiz faciebat..."

Evangelista de la localidad gaditana de Tarifa ${ }^{19}$.

Hasta aquí el análisis y estudio de la imagen de Santa Teresa de Alcaudete. Desde estas líneas confiamos en una mayor y contundente reivindicación de la obra de Ortiz ya que estamos convencidos de que aúna requisitos y méritos más que suficientes para ser considerado como uno de los escultores más destacados del siglo XVIII español, actuando como auténtico nexo entre las corrientes barrocas y el gusto clasicista que comenzaba a irradiar la Real Academia de San Fernando. Su variedad escultórica y la valía de las obras que han llegado a nuestros días, bien sea la obra en sí o bien mediante fotografías de las piezas desaparecidas en 1931 y 1936, lo colocan indiscutiblemente en la primera fila de los escultores del momento. 